Original Research Article

\title{
Assessment of drug-drug interactions in the prescription of elderly patients on cardiovascular drugs
}

\author{
Sneha C., Anuradha H. V.*, Srihari G. Kulkarni
}

Department of Pharmacology, MS Ramaiah Medical College and Hospital, Bangalore, Karnataka, India

Received: 08 March 2019

Revised: 30 March 2019

Accepted: 06 April 2019

*Correspondence to:

Dr. Anuradha HV,

Email:

dranuradhapharmac@gmail.com

Copyright: (C) the author(s), publisher and licensee Medip Academy. This is an openaccess article distributed under the terms of the Creative Commons Attribution NonCommercial License, which permits unrestricted noncommercial use, distribution, and reproduction in any medium, provided the original work is properly cited.

\begin{abstract}
Background: Cardiovascular disease is one of the major causes of mortality and morbidity in a developing country like India. These patient's prescription contains multiple drugs to reduce the mortality and morbidity and they also contain drugs for treatment of co morbidities leading to polypharmacy. The main objective of the study was to identify the pattern of drug-drug interaction (DDI) in patients on cardiovascular drugs with various co existing morbidities.

Methods: This study was conducted in the Department of General Medicine of a tertiary care center. Prescription of 200 patients were analysed for demographic details like gender, age, comorbidities and drugs prescribed. DDI were assessed using Micromedex software.

Results: In this study, conducted on the prescription of 200 elderly patients, 13 $(66 \%)$ prescription had 408 DDI, of which 158 (39\%) were major, $246(60 \%)$ were moderate and $1(0.02 \%)$ was contraindicated and $3(0.007 \%)$ were minor. Conclusions: It can be concluded from the present study that the risk of DDI increases with the increase in number of drugs in the prescription and there is increase in number of drugs in the prescription with the increase in number of co morbidities. The antiplatelet and anticoagulant group of drugs were responsible for majority of DDI, followed by antihypertensives and hypoglycaemic agents. Most of these DDI could be avoided with slight modification in the dosage regimen based on the pharmacokinetics and pharmacodynamics of the drug.
\end{abstract}

Keywords: Cardiovascular drugs, Drug-drug interaction, Major interaction, Moderate interaction

\section{INTRODUCTION}

Drug-drug interaction (DDI) refers to modification of response to one drug by another drug when they are administered simultaneously. The modification is mostly quantitative where the response is either increased or decreased in intensity but sometimes it is qualitative, hence abnormal or a different type of response is produced. The possibility of DDI arises whenever a patient receives more than one drug and chances increase with number of drugs taken. ${ }^{1}$ There are numerous potential DDIs that can result in toxicity, alteration of the desired therapeutic effects and even can lead to life threatening condition. Drug-specific factors like dose, route of administration, drug formulation and the sequence of drug administration can be determinants of DDI. ${ }^{2}$

As per National Policy on older persons adopted by Government of India, elderly or geriatric is defined as a person who is of age 60 years or above. According to official population projections, the number of Indian elderly will raise to approximately 140 million by $2021 .^{3}$ 
Polypharmacy is defined as concomitant use of more than two medication. ${ }^{4}$ Polypharmacy practice is common in elderly as they are usually having comorbid illnesses. Polypharmacy and complicated drug regimens used for treating the comorbidities in an elderly lead to DDIs and adverse drug reactions. Studies have confirmed polypharmacy as one of the major risk factors in precipitation of DDIs. ${ }^{5}$ The elderly population are at increased risk because of decreased functioning of the systems, more number of medications due to comorbidities and multiple drug regimes. Sometimes inappropriate prescribing patterns may lead to poly pharmacy. ${ }^{6}$

\section{DDI are classified as $^{7}$}

- Contraindicated- drugs contraindicated for concurrent use.

- Major- interaction may be life threatening and or require medical intervention to minimize or prevent serious adverse events.

- Moderate- interaction may result to exacerbation of patient's condition and or require an alteration in the therapy.

- Minor- interaction would have limited clinical effects, may include increase in frequency or severity of side effects but generally would not require major alteration in the therapy.

\section{METHODS}

In this cross-sectional study, the data was collected from 200 geriatric inpatients prescriptions admitted to M.S. Ramaiah Hospital, Bangalore, Karnataka, India. Institutional ethics committee approval was obtained. Study period was from March 2015 to March 2016. This study included all elderly in patients on cardiovascular drugs, who were admitted to medicine ward. The critically ill patients in the intensive care were excluded from the study. The out patients were not included in the study. Patient's demographics, pre-existing diseases and drug history were recorded. Drug-Drug interactions were assessed using Micromedex software on reviewing patient's case records. All the quantitative variables like age were expressed as mean and standard deviation. All the qualitative variables were expressed as proportion.

This study was conducted by analysing all the prescriptions of geriatric inpatients admitted in MS Ramaiah Hospital, Bangalore, Karnataka, India. The prescriptions were assessed on the basis of demography and drugs prescribed. All the prescriptions will be evaluated for polypharmacy and drug interactions. Drugdrug interactions was assessed through Micromedex software. ${ }^{8}$

In the present study, expecting $95 \%$ confidence level $10 \%$ relative precision, the study requires a minimum of 181 subjects. Descriptive statistics were analysed and presented in terms of mean, standard deviation and percentage. Chi-square test was used to study the association of age and gender with polypharmacy and DDIs. SPSS version 20 was used to analyse the data.

\section{RESULTS}

A total of 200 prescriptions of elderly patients were analysed. All the quantitative variables like age were expressed as mean and standard deviation. All the qualitative variables were expressed as proportion. There were $73 \%(n=126)$ male patients and $37 \%(n=74)$ female patients in this study (Table 1).

Table 1: Age distribution.

\begin{tabular}{|ll|}
\hline Age (years) & n (number) \\
\hline $60-69$ & $139(70 \%)$ \\
\hline $70-79$ & $52(26 \%)$ \\
\hline $80-89$ & $08(4 \%)$ \\
\hline$>90$ & $01(0.5 \%)$ \\
\hline
\end{tabular}

In these 200 prescriptions, 408 interactions were found. The age of this population ranged from 60 to 93 years. The mean age of the patients was $69.19 \pm 6.99$ years. The number of drugs used per patient ranged from a minimum of 1 to a maximum of 10 drugs. The patients were on various groups of drugs acting on the cardiovascular system as follows:

- Antihypertensives- calcium channel blockers, beta blockers, ACE inhibitors, angiotensin receptor blockers, alpha blockers,

- Diuretics- loop diuretics, thiazides, potassium sparing diuretics, osmotic diuretics,

- Drugs with positive ionotropic effects- digoxin,

- Antiplatelet agents- aspirin, clopidogrel,

- Hypolipidemics- statins, fibrates,

- Vasodilators- nitrates, potassium channel activators,

- Electrolytes,

- Thyroid and antithyroid agents,

- Anticoagulants.

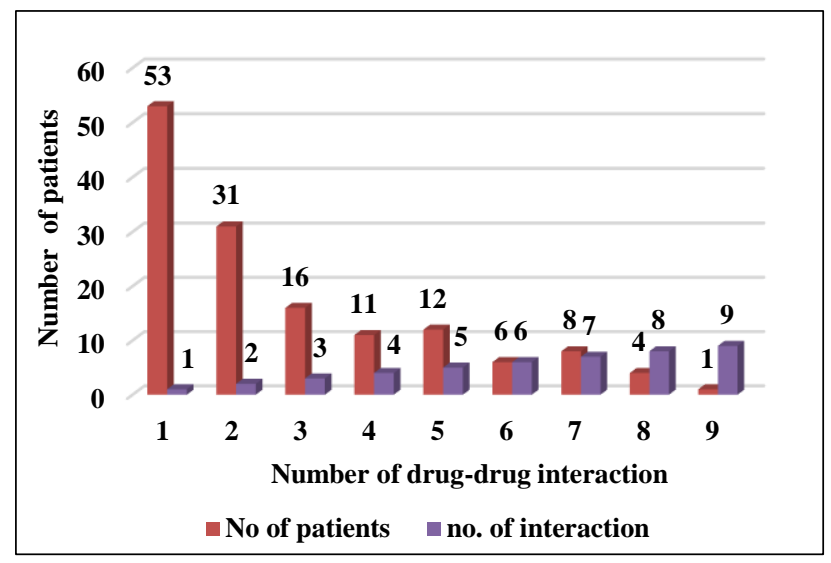

Figure 1: Number of interactions. 
Table 2: Frequency and effects of DDIs due to cardiovascular drugs.

\begin{tabular}{|lll|}
\hline Drugs & Interactions & No. of patients (n) \\
\hline Aspirin+Clopidogrel & Increases risk of bleeding & 38 \\
\hline Atorvastatin+Clopidogrel & Decreases antiplatelet effect & 32 \\
\hline Aspirin+Insulin & Increases hypo/hyperglycaemia risk & 17 \\
\hline Aspirin+Furosemide & Decreases diuretic efficacy & 16 \\
\hline Aspirin+Metoprolol & Decreases antihypertensive efficacy & 16 \\
\hline Metoprolol+Insulin & Masks symptoms of hypoglycaemia & 07 \\
\hline Telmisartan+Insulin & Increases risk of hypoglycaemia & 04 \\
\hline Aspirin+Ramipril & Decreases antihypertensive efficacy & 10 \\
\hline Aspirin+Cilostazol & Increases risk of bleeding & 07 \\
\hline Amlodipine+Clopidogrel & Decreases antiplatelet efficacy & 04 \\
\hline Ramipril+Metformin & Increases risk of hypoglycaemia & 04 \\
\hline Aspirin+Enalapril & Decreases antihypertensive efficacy & 08 \\
\hline Ramipril+Spironolactone & Increased risk of hyperkalaemia & 07 \\
\hline Ramipril+Insulin & Increases risk of hypoglycaemia & 04 \\
\hline Insulin+Metformin & Increases risk of hypoglycaemia & 06 \\
\hline Insulin+Levofloxacin & Impaired glycaemic control & 06 \\
\hline Insulin+Losartan & Increases risk of hypoglycaemia & 04 \\
\hline Other combination with cardiovascular drugs with less than or equal to frequency of 4 DDI & 218 \\
\hline Total DDIs & 408 & \\
\hline
\end{tabular}

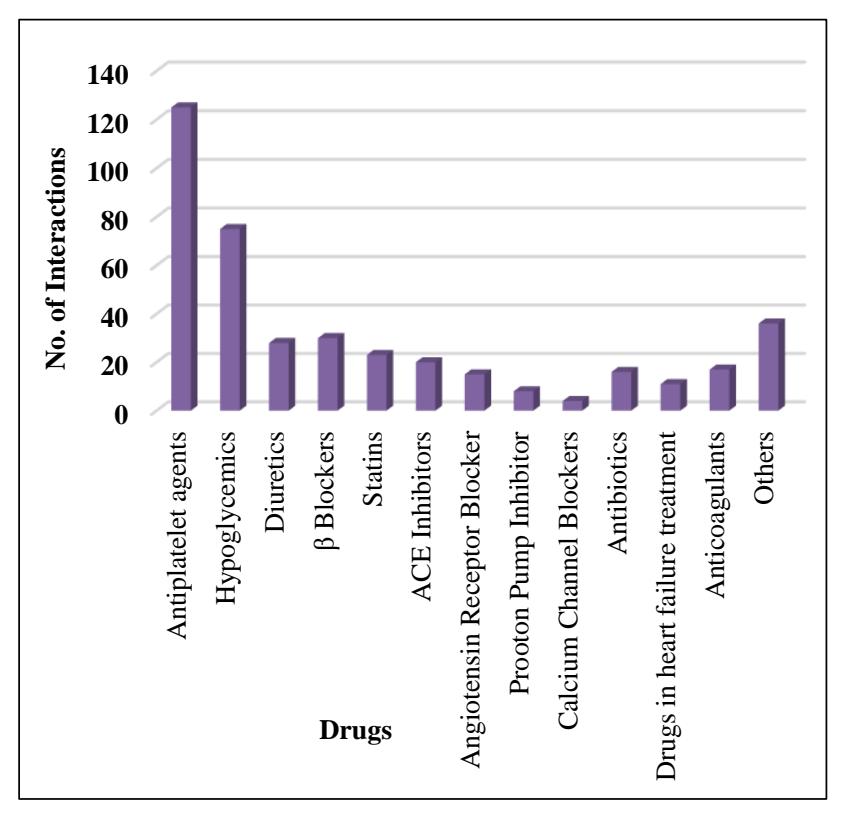

Figure 2: Different group of drugs involved in the interaction.

Table 3: Classification of DDI.

\begin{tabular}{|lll|}
\hline Category & n & Percentage \\
\hline Contraindicated & 1 & $0.002 \%$ \\
\hline Major & 158 & $39 \%$ \\
\hline Moderate & 246 & $60 \%$ \\
\hline Minor & 3 & $0.007 \%$ \\
\hline Total & 408 & \\
\hline
\end{tabular}

Figure 1 shows the number of interactions per prescription. Atleast $53(27 \%)$ prescriptions were found to have at least one interaction.

On statistical analysis of age of patient and number of drugs by Pearson's Chi Square test, $p$ was significant at less than 0.0001 , hence there was statistically significant difference between the age and the number of drugs in the prescription, and the number of drugs increased with the increase in age. As the age increased the risk of co-morbid illness also increased, so the number of drugs in the prescription also increased. But there was no statistically significant difference in the occurrence of DDI among male and female $(p=0.3)$. The drugs that were prescribed for co morbid illness like diabetes mellitus, bronchial asthma, seizure disorder, gastro oesophageal reflux disorder, peptic ulcer disease, peripheral vascular disease, acute infections etc. would often interact with different groups of drugs acting on cardiovascular system. The interacting drugs belonged to various pharmacological classes like- proton pump inhibitors, H2 blockers, beta agonists, antiepileptics, oral hypoglycemics, insulin, prokinetic agents and antibiotics. It was found that the antiplatelet agent, aspirin (33\%) was the most common drug to be involved in DDI, followed by insulin (20\%). Aspirin would interact with antihypertensives and diuretics and blunt their therapeutic efficacy.

The drugs would interact with insulin and would either increase the risk of hypo/hyperglycemia. These DDI might reduce the quality of life and also add on to the disease burden. Table 2 shows the different DDI caused by various 
drugs. Figure 2 shows the different group of drugs involved in DDI. Majority of the interactions were moderate in nature. Table 3 depicts the classification of 408 interactions found in the prescription.

\section{DISCUSSION}

This study involved 200 prescriptions of elderly patients on cardiovascular drugs, of which 74 were female and 126 were male. In this study, the prescription contained minimum of one drug to a maximum of 11 drugs. These prescriptions contained more than 70 different types of drugs of them about 40 drugs were acting on the cardiovascular system which belong to the following classes: antiplatelet agents like aspirin, clopidogrel and cilostazol, antihypertensives like CCBs amlodipine and clinidipine, ARBs- telmisartan, olmesartan and losartan, ACEIs- enalapril and ramipril, $\beta$ blockers- atenolol, metoprolol, propranolol, carvedilol and $\alpha$ blockers like prazosin, $\alpha$ agonists- clonidine, moxonidine, diureticsthiazides, furosemide, torsemide, spironolactone, metolazone, antianginals like nitrates and drugs like digoxin, ivabradine and ranolazine were used in heart failure. More than 65 pairs of DDI were found. The minimum number of DDI per patient was 1 in 53 patients and the maximum was 9 in one patient who was on 11 drugs (Figure 1). $246(60 \%)$ of the DDI were moderate in nature and 158 (39\%) were major DDI, Table 3 illustrates the effects of these DDI. Antiplatelets were the most common drugs responsible for the DDI where they increased the risk of bleeding when used with other anticoagulants and also diminished response of various other drugs (Figure 2). In a study conducted by Sharma $\mathrm{S}$ et al, a total of 48 DDI was identified in 150 patients. Among them 32 were identified with at least one interacting combination. $20(65.5 \%)$ were identified with single interacting combination, this was followed by the patients who encountered two DDI in $8(25 \%)$ patients and three interactions in $4(12.5 \%)$ pateints. ${ }^{9}$

Polypharmacy is a major cause of DDI. According to the analysis of SAGE (Study on global aging) data by Dutta M et al, the prevalence of polypharmacy was $4.2 \%$ among elderly in India. This study also showed higher proportion of polypharmacy among male, aged $70-79$ years. ${ }^{10}$ But in present study polypharmacy was more prevalent in the age group 60-69 years. Ahmad A et al, have concluded in a study that out of 404 records reviewed, 78 (19.3\%) patients had potential DDI and out of these 74 (54\%) were moderate in nature. ${ }^{11}$ According to Pelliccia F et al study, states that DDI contributed for the inconsistency in the efficacy of clopidogrel to prevent atherothrombotic events. ${ }^{12}$ According to Corsonello A et al, infections in elderly have increased rate of mortality and morbidity because of the polypharmacy regimens which increase the risk of DDI. Additionally, changes in the body composition occurring with advance in age, reduced liver function and perfusion, reduced renal excretion affects the pharmacokinetics and pharmacodynamics. ${ }^{13}$ Hence, DDI and ADR contribute to a significant health issue worldwide. ${ }^{14}$ Polypharmacy may indirectly lead to hospital readmissions increasing the morbidity and mortality. ${ }^{15}$ Over the counter medication and non-prescription drugs significantly contribute to polypharmacy and DDI. ${ }^{16}$ Lesser the number of drugs prescribed, lesser the chance of inappropriate medication and DDI. ${ }^{17}$ Additionally, there is a controversial role of alternative system of preventive medicine, where yoga can help treat insomnia, stress and control of blood glucose and blood pressure may reduce the number of drugs and their frequency of administration in the elderly patients, hence may reduce the risk of DDI. ${ }^{18-21}$ The alternative system of herbal medicines further poses the risk of herbal-drug interactions by altering the pharmacokinetics and pharmacodynamics of the drugs. These herbal medications however have intrinsic variation amongst themselves in active drug composition. ${ }^{22}$ The drug-gene interaction is the newest concept that requires further reasoning on its impact on pharmacokinetic variations in the absorption, metabolism and excretion of the drug. Therefore, thorough understanding of P450 isoenzymes and drug transporters may lead to new methods to prevent clinically relevant drug interactions. ${ }^{23,24}$ Tailor made drug therapy, based on the pharmacogenomics of individual patient may be the solution to eliminate such drug-gene interaction. ${ }^{25}$

\section{CONCLUSION}

Polypharmacy increases the risk of drug-drug interactions, most of these can be minimizes by pharmacokinetic and pharmacodynamic modification of the drug regimen. This also reduces the incidence of adverse drug reactions due to drug-drug interactions and also reduces the morbidity and mortality. Coordination between the clinician and the clinical pharmacologists plays an essential role in optimized prescription.

\section{ACKNOWLEDGEMENTS}

Authors would like to thank MS Ramaiah Medical college, Karnataka, India for approving the study and Department of Pharmacology and General Medicine, for their support during study.

\section{Funding: No funding sources}

Conflict of interest: None declared

Ethical approval: The study was approved by the Institutional Ethics Committee

\section{REFERENCES}

1. KD Tripathi. Textbook of Pharmacology. 7th ed. New Delhi: Jaypee brothers medical publishers; 2013: 728734.

2. Katzung and Trevor. Important drug interaction and their mechanism. Basic and Clinical Pharmacology 13th ed. Mc Graw Hill; 2016:1522.

3. Central Statistics Office, Ministry of Statistics and Programme Implementation, Government of India. Situation analysis of elderly in India; 2011. Available at: 
http://www.mospi.nic.in/mospi_new/upload/elderly_i n_India.pdf. Accessed on 26 March 2019.

4. SS M, MK S, Vishnu VG, Jose F, Siraj ST, Anand VP. The prevalence of polypharmacy in south indian patients: a pharmacoepidemiological approach. Ind $\mathbf{J}$ Pharm Prac. 2012;5(3):40.

5. Kevin C. Osterhoudt and Trevor M. Penning. Drug toxicity and poisoning. In: Brunton LL, Chabner BA, Knollman BC. eds. Goodman and Gillman's- The Pharmacological Basis of Therapeutics. 12th ed. New York: Mc Graw Hill; 2011: 96-97.

6. Fadare JO, Agboola SM, Opeke OA, Alabi RA. Prescription pattern and prevalence of potentially inappropriate medications among elderly patients in a Nigerian rural tertiary hospital. Therapeutics Clin Risk Man. 2013;9:115.

7. Sharma HL, Sharma KK. Principles of Pharmacology. 3rd ed. Hyderabad: Paras publishers; 2017.

8. IBM Micromedex®. Truven Health Micromedex Solutions 2016. Available at: https://www.micromedexsolutions.com/. Accessed on January 16, 2019.

9. Sharma S, Chhetri HP, Alam K. A study of potential drug-drug interactions among hospitalized cardiac patients in a teaching hospital in Western Nepal. Ind $\mathbf{J}$ Pharmacol. 2014;46(2):152.

10. Dutta M, Prashad L. Prevalence and risk factors of polypharmacy among elderly in india: evidence from SAGE data. Int J Public Ment Health Neurosci. 2015;2(2):11-6.

11. Ahmad A, Khan MU, Haque I, Ivan R, Dasari R, Revanker M, et al. Evaluation of potential drug-drug interactions in general medicine ward of teaching hospital in southern India. J Clin Diagn Res JCDR. 2015;9(2):FC10.

12. Pelliccia F, Rollini F, Marazzi G, Greco C, Gaudio C, Angiolillo DJ. Drug-drug interactions between clopidogrel and novel cardiovascular drugs. Euro J Pharmacol. 2015;765:332-6.

13. Corsonello A, Abbatecola AM, Fusco S, Luciani F, Marino A, Catalano S, et al. The impact of drug interactions and polypharmacy on antimicrobial therapy in the elderly. Clin Microbiol Inf. 2015;21(1):20-6.

14. Bucşa C, Farcaş A, Cazacu I, Leucuta D, AchimasCadariu A, et al. How many potential drug-drug interactions cause adverse drug reactions in hospitalized patients?. Euro J Internal Med. 2013;24(1):27-33.

15. Sehgal V, Bajwa SJ, Sehgal R, Bajaj A, Khaira U, Kresse V. Polypharmacy and potentially inappropriate medication use as the precipitating factor in readmissions to the hospital. J Fam Med Prim Care. 2013;2(2):194.

16. Kim HA, Shin JY, Kim MH, Park BJ. Prevalence and predictors of polypharmacy among Korean elderly. PloS One. 2014;9(6):e98043.

17. Basnet S, Paudel KR, Sah AK, Jha RK, Sah P, Adhikari S, et al. Prescribing pattern, polypharmacy and potentially inappropriate prescribing in hospitalized elderly patients: a retrospective study in a teaching hospital in Nepal. Int J Sci Rep. 2016;2(1):712.

18. Pallav S. Health impacts of yoga and pranayama: a state-of-the-art review. Int J Prev Med. 2012;3(7):44458.

19. Saatcioglu F. Regulation of gene expression by yoga, meditation and related practices: a review of recent studies. Asian J Psychiatry. 2013;6(1):74-7.

20. Bhasin MK, Dusek JA, Chang BH, Joseph MG, Denninger JW, Fricchione GL, et al. Relaxation response induces temporal transcriptome changes in energy metabolism, insulin secretion and inflammatory pathways. PloS One. 2013;8(5):e62817.

21. Marshall H, Rebecca S, Terry Selfe KI. Effectiveness of yoga for hypertension: systematic review and metaanalysis. Evid Based Complement Alternat Med. 2013;649836.

22. Bhadra R, Ravakhah K, Ghosh RK. Herb-drug interaction: the importance of communicating with primary care physicians. Aus Med J. 2015;8(10):315.

23. Tannenbaum C, Sheehan NL. Understanding and preventing drug-drug and drug-gene interactions. Expert Rev Clin Pharmacol. 2014;7(4):533-44.

24. Verbeurgt P, Mamiya T, Oesterheld J. How common are drug and gene interactions? prevalence in a sample of 1143 patients with CYP2C9, CYP2C19 and CYP2D6 genotyping. Pharmacogen. 2014;15(5):65565.

25. Thirumaran RK, Heck JW, Hocum BT. CYP450 genotyping and cumulative drug-gene interactions: an update for precision medicine. Per Med. 2016;13(1):58.

Cite this article as: Sneha $\mathrm{C}$, Anuradha HV, Kulkarni SG. Assessment of drug-drug interactions in the prescription of elderly patients on cardiovascular drugs. Int J Basic Clin Pharmacol 2019;8:1078-82. 